\title{
Factors predicting peritoneal recurrence in advanced gastric cancer: implication for adjuvant intraperitoneal chemotherapy
}

\author{
Ju-Hee Lee $\cdot$ Sang-Yong Son $\cdot$ Chang Min Lee $\cdot$ \\ Sang Hoon Ahn $\cdot$ Do Joong Park $\cdot$ Hyung-Ho Kim
}

Received: 4 February 2013/ Accepted: 26 September 2013/Published online: 8 October 2013

(c) The International Gastric Cancer Association and The Japanese Gastric Cancer Association 2013

\begin{abstract}
Background Despite adjuvant chemotherapy, patients with advanced gastric cancer (AGC) often develop recurrence, and the peritoneum is the most common site of recurrence. Therefore, intraperitoneal chemotherapy (IPC) has been proposed as a treatment option. The aim of this study was to select the eligible patients for application of IPC.

Methods A total of 805 patients with AGC who underwent curative D2 gastrectomy between May 2003 and December 2009 were included in this study. Risk factors for peritoneal recurrence were analyzed.

Results Recurrence developed in 245 patients (30.4\%). The first site of recurrence was the peritoneum in 144 patients (58.8\%), and the 5-year peritoneal recurrence-free survival was $79.3 \%$. Depth of tumor invasion $\geq \mathrm{T} 3$, extensive lymph node metastasis (N3), Bormann type 4, infiltrative type (Ming's classification), and venous invasion were independent risk factors for peritoneal recurrence. In subgroup analysis with patients who had received adjuvant chemotherapy $(n=481)$, depth of tumor invasion $\geq \mathrm{T} 3$, Bormann type 4, infiltrative type (Ming's classification), and venous invasion were independent risk factors for peritoneal recurrence. When a peritoneal recurrence risk index was made with each risk factor assigned 1 point
\end{abstract}

J.-H. Lee · S.-Y. Son · C. M. Lee · S. H. Ahn ·

D. J. Park - H.-H. Kim ( $\)$

Department of Surgery, Seoul National University Bundang

Hospital, 166 Gumi-ro, Bundang-gu, Seongnam-shi,

Gyeonggi-do 463-707, South Korea

e-mail: hhkim@snubh.org

D. J. Park · H.-H. Kim

Department of Surgery, Seoul National University College of

Medicine, Seoul, South Korea
( 2 points for $\mathrm{T} 4$ stage), peritoneal recurrence rates with 0 , $1,2,3,4$, or 5 points were $0 \%, 3.9 \%, 13.1 \%, 33.3 \%$, $44.0 \%$, and $72.0 \%$, respectively, in those patients.

Conclusions Patients at higher risk for peritoneal recurrence can be identified from the findings of this study. Further prospective studies are required to evaluate the usefulness of IPC for these patients.

Keywords Advanced gastric cancer - Peritoneal recurrence $\cdot$ Intraperitoneal chemotherapy

\section{Introduction}

Although the incidence of gastric cancer has decreased, it is still the second most common cause of cancer-related death $[1,2]$. Gastric cancer is often diagnosed as an advanced stage, and R0 resection is still the mainstay of treatment. Patients with advanced gastric cancer (AGC) often develop recurrence after curative resection, and in these cases, peritoneal dissemination is the most common pattern of recurrence [3]. Peritoneal dissemination is still the most common pattern of recurrence even in patients who receive adjuvant chemotherapy, although adjuvant chemotherapy definitely improves overall survival [4-6]. Some chemotherapeutic drugs, such as paclitaxel, are considered to be effective for peritoneal metastasis because of the efficient peritoneal penetration from the blood [7]; however, most systemic chemotherapeutic agents are not effective for peritoneal recurrence because of the bloodperitoneum barrier. In this regard, intraperitoneal chemotherapy (IPC) can be considered as an additional adjuvant therapy for AGC.

IPC offers a theoretical advantage over systemic therapy by delivering a high concentration of drug directly to the 
peritoneal cavity, with reduced systemic toxicity $[8,9]$. Several studies have reported that IPC was effective as prophylactic and therapeutic treatment of peritoneal dissemination [10-14]. However, many controversies remain unsolved: timing of drug delivery (preoperative, intraoperative, postoperative), use of hyperthermic or normothermic conditions, optimal choice of chemotherapeutic agent for gastric cancer, and efficacy of peritonectomy or cytoreductive surgery with IPC for AGC with macroscopic peritoneal seeding [15]. Further prospective studies on IPC are needed to make definitive recommendations.

For efficient adjuvant treatment of peritoneal metastasis, future clinical trials on adjuvant IPC should be limited to patients who are at an increased risk of developing peritoneal recurrence because it can be easily surmised that those patients would benefit from adjuvant IPC. This study was performed to analyze the risk factors for peritoneal recurrence and to determine the target patients for adjuvant IPC.

\section{Materials and methods}

Patients who underwent surgery for gastric cancer between May 2003 and December 2009 at Seoul National University Bundang Hospital were included in the study. Patients were selected from a prospective gastric cancer database according to the following criteria: (1) pathologically proven gastric adenocarcinoma, (2) AGC (pT $\geq \mathrm{T} 2$ ), (3) patients had undergone curative D2 lymphadenectomy as described in the Japanese classification of gastric carcinoma [16], (4) no distant metastasis, and (5) no history of other therapy for gastric cancer. Patients who died of complications after surgery were excluded. All cases were restaged retrospectively according to the 7th edition of AJCC/UICC TNM staging. Adjuvant systemic chemotherapy was recommended in all patients with stage II or III disease according to the 6th edition of the AJCC/UICC staging system. Those patients received 5-FU-based adjuvant chemotherapy such as FOLFOX [a 2 -h infusion of oxaliplatin $\left(100 \mathrm{mg} / \mathrm{m}^{2}\right)$ and leucovorin $\left(100 \mathrm{mg} / \mathrm{m}^{2}\right)$, followed by a 46-h continuous infusion of $5-\mathrm{FU}(2,400 \mathrm{mg} /$ $\mathrm{m}^{2}$ ), repeated every 2 weeks for up to 12 cycles], or FP/XP/ SP [cisplatin at a dose of $60 \mathrm{mg} / \mathrm{m}^{2}$ infusion on day 1 in combination with capecitabine $\left(1,000 \mathrm{mg} / \mathrm{m}^{2}\right.$ bid p.o. on days $1-14, \mathrm{XP}), \mathrm{S}-1$ (40 $\mathrm{mg} / \mathrm{m}^{2}$ bid p.o. on days $\left.1-21, \mathrm{SP}\right)$, or 5 -FU $\left(800-1,000 \mathrm{mg} / \mathrm{m}^{2}\right.$ IV drip on days $1-5$ as a protracted continuous infusion, FP), repeated every 3 weeks (XP and FP) or every 5 weeks (SP) for at least 6 cycles], or capecitabine $\left[1,250 \mathrm{mg} / \mathrm{m}^{2}\right.$ twice daily $\left(2,500 \mathrm{mg} / \mathrm{m}^{2} /\right.$ day $)$ for 14 days followed by 7 days of rest, for up to 6 cycles], or S-1 $\left[40 \mathrm{mg} / \mathrm{m}^{2}\right.$ bid on days $1-28$ every 6 weeks for 1 year], or tegafur-uracil [UFT, $180 \mathrm{mg} / \mathrm{m}^{2}$ twice daily
(360 mg/m $/ \mathrm{m}^{2} /$ day) p.o. for 21 days followed by a 7-day rest period for 1 year], or XELOX [oral capecitabine $\left(1,000 \mathrm{mg} / \mathrm{m}^{2}\right.$ twice daily on days $1-14$ of each cycle) plus intravenous oxaliplatin $\left(130 \mathrm{mg} / \mathrm{m}^{2}\right.$ on day 1 of each cycle), repeated every 3 weeks for up to 8 cycles], or FM (5-FU $350 \mathrm{mg} / \mathrm{m}^{2}$ IV on days $1-5$ and $29-33$, and mitomycin-C $10 \mathrm{mg} / \mathrm{m}^{2}$ IV bolus injection on day 1 , repeated every 8 weeks, for up to 6 cycles).

Follow-up was conducted in the outpatient clinic until death or cutoff date (March 31, 2012). Follow-up evaluation included physical examination and laboratory tests (including tumor markers such as carcinoembryonic antigen and CA19-9). Chest radiography, ultrasonography, abdominal and pelvic computed tomography (CT) scanning, and endoscopy were performed once or twice a year until 2 years after surgery and then annually thereafter. Positron emission tomography (PET) or histological examination was sometimes performed for patients with recurrence. Peritoneal recurrence was diagnosed mainly by CT scan and sometimes confirmed by diagnostic laparoscopy or ascites cytology. CT findings identified as peritoneal seeding included the following: massive ascites, enhanced nodules located in the abdominal or pelvic cavity, abnormal wall thickness of the intestine, increased fat density of the intestinal mesentery, diffuse hydronephrosis, peri-biliary tumor infiltration causing obstruction of bile duct or Krukenberg tumors. Hematogenous and distant lymph node (paraaortic, mesenteric, and extraabdominal lymph nodes) metastases were classified as distant metastasis.

Statistical analyses were performed using SPSS version 18.0 (SPSS, Chicago, IL, USA). Statistically significant differences were analyzed by the chi-square test and independent Student's $t$ test. Survival rates and cumulative incidence rates were calculated using the Kaplan-Meier method and compared with the log-rank test. Cox proportional hazards regression was used to determine the impact of variables on peritoneal recurrence-free survival. Receiver operating characteristic (ROC) curve area analysis [area under the curve (AUC)] was performed to examine diagnostic accuracy of peritoneal recurrence risk indexes, and the constructed models were compared using dBSTAT for windows (version 4.1, www.dbstat.com). $p<0.05$ was considered statistically significant.

\section{Results}

According to eligible criteria, 817 patients were selected. Twelve patients were lost to follow-up immediately after surgery. Those patients were excluded from the analysis. The median follow-up period was 41.7 months (range, 4.07-99.4). 


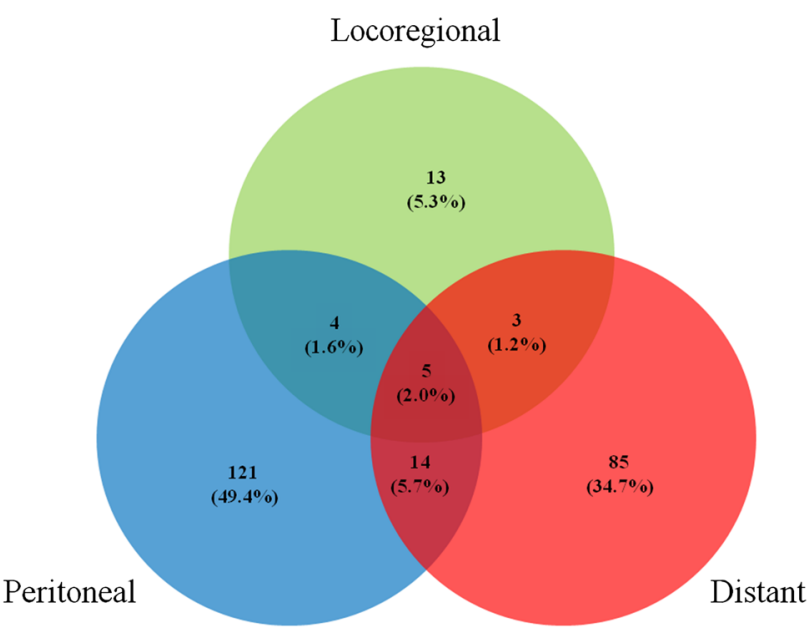

Fig. 1 Recurrence patterns in 245 patients after curative resection for advanced gastric cancer

The first sites of recurrence at the time of diagnosis in 245 patients with recurrent disease are shown in Fig 1. Peritoneal recurrence was observed most frequently $(n=144, \quad 58.8 \%)$, followed by distant metastasis $(n=111,45.3 \%)$ and locoregional recurrence $(n=25$, $10.2 \%$ ). To observe the clinicopathological features of patients with peritoneal recurrence, patients with peritoneal recurrence ( $n=144$, group A) were compared with the patients who had distant metastasis without peritoneal recurrence at the time of recurrence $(n=88$, group B) (Table 1). Age at the time of operation, distribution of Bormann type, histological grade, Lauren's classification, Ming's classification, presence of venous invasion, and pT stage were significantly different between the two groups. The estimated median survival time after recurrence was 9.4 months in group A and 14.6 months in group B. There was a significant difference in survival rates after recurrence according to recurrence patterns (Fig. 2).

The 5-year peritoneal recurrence-free survival was $79.3 \%$. When the cumulative incidence of peritoneal recurrence was compared according to clinicopathological factors, a significant difference was observed in Bormann type, tumor size, histological grade, Lauren's classification, Ming's classification, lymphatic and venous invasion, $p T$ and $\mathrm{pN}$ stages, and surgical approach (open vs. laparoscopy). In multivariate analysis, Bormann type 4 gastric cancer, infiltrative type in Ming's classification, venous invasion, tumor invasion depth $(\geq \mathrm{T} 3)$, and extensive lymph node metastasis (N3) were independent risk factors for peritoneal recurrence (Table 2).

Of 629 patients with stage II and III according to the UICC/AJCC 6th edition, 481 received adjuvant chemotherapy. When the risk factors related to peritoneal recurrence were analyzed in patients who had received adjuvant systemic chemotherapy, Bormann type 4 gastric cancer,
Table 1 Comparison of clinical factors according to pattern of recurrence

\begin{tabular}{|c|c|c|c|}
\hline Factor & $\begin{array}{l}\text { Group A } \\
(n=144) \\
n(\%)\end{array}$ & $\begin{array}{l}\text { Group B } \\
(n=88) \\
n(\%)\end{array}$ & $p$ \\
\hline Age (years \pm SD) & $57.01 \pm 14.107$ & $63.48 \pm 12.28$ & $<0.001$ \\
\hline Sex & & & 0.483 \\
\hline Male & $90(62.5)$ & $59(67.0)$ & \\
\hline Female & $54(37.5)$ & $29(33.0)$ & \\
\hline Bormann type & & & $<0.001$ \\
\hline 1 & $1(0.7)$ & $7(8.0)$ & \\
\hline 2 & $16(11.1)$ & $18(20.5)$ & \\
\hline 3 & $78(54.2)$ & $54(61.4)$ & \\
\hline 4 & $49(34.0)$ & $8(9.1)$ & \\
\hline Unclassified & $0(0)$ & $1(1.1)$ & \\
\hline Tumor size & & & 0.379 \\
\hline$\leq 5 \mathrm{~cm}$ & $35(24.3)$ & $26(29.5)$ & \\
\hline$>5 \mathrm{~cm}$ & 109 (75.7) & $62(70.5)$ & \\
\hline Histological grade & & & $<0.001$ \\
\hline Differentiated & $28(19.4)$ & $43(48.9)$ & \\
\hline Undifferentiated & $116(80.6)$ & $45(51.1)$ & \\
\hline Lauren & & & $<0.001$ \\
\hline Intestinal & $27(18.8)$ & $39(44.3)$ & \\
\hline Diffuse & $110(76.4)$ & $38(43.2)$ & \\
\hline Mixed & $7(4.9)$ & $11(12.5)$ & \\
\hline Ming & & & $<0.001$ \\
\hline Infiltrative & $139(96.5)$ & $70(79.5)$ & \\
\hline Expanding & $5(3.5)$ & $18(20.5)$ & \\
\hline Lymphatic & & & 0.08 \\
\hline Negative & $25(17.4)$ & $8(9.1)$ & \\
\hline Positive & $119(82.6)$ & $80(90.9)$ & \\
\hline Venous invasion & & & 0.134 \\
\hline Negative & $84(58.3)$ & $60(68.2)$ & \\
\hline Positive & $60(41.7)$ & $28(31.8)$ & \\
\hline pT stage & & & $<0.001$ \\
\hline $\mathrm{T} 2$ & $3(2.1)$ & $16(18.2)$ & \\
\hline $\mathrm{T} 3$ & $34(23.6)$ & $40(45.5)$ & \\
\hline $\mathrm{T} 4 \mathrm{a}$ & $94(65.3)$ & $24(27.3)$ & \\
\hline $\mathrm{T} 4 \mathrm{~b}$ & $13(9.0)$ & $8(9.1)$ & \\
\hline pN stage & & & 0.38 \\
\hline N0 & $14(9.7)$ & $8(9.1)$ & \\
\hline N1 & $16(11.1)$ & $5(5.7)$ & \\
\hline $\mathrm{N} 2$ & $25(17.4)$ & $12(13.6)$ & \\
\hline N3 & $89(61.8)$ & 63 (71.6) & \\
\hline pStage & & & 0.065 \\
\hline IB & $0(0)$ & $3(3.4)$ & \\
\hline IIA & $6(4.2)$ & $4(4.5)$ & \\
\hline IIB & $12(8.3)$ & $8(9.1)$ & \\
\hline IIIA & $18(12.5)$ & $14(15.9)$ & \\
\hline IIIB & $40(27.8)$ & $32(36.4)$ & \\
\hline IIIC & $68(47.2)$ & $27(30.7)$ & \\
\hline
\end{tabular}


Table 1 continued

\begin{tabular}{llll}
\hline Factor & $\begin{array}{l}\text { Group A } \\
(n=144) \\
n(\%)\end{array}$ & $\begin{array}{l}\text { Group B } \\
(n=88) \\
n(\%)\end{array}$ & $p$ \\
\hline Adjuvant chemotherapy & $112(77.8)$ & $64(72.7)$ & 0.383 \\
FOLFOX & 17 & 9 & \\
Capecitabine/S1/UFT & $4 / 17 / 7$ & $4 / 10 / 7$ & \\
XP/FP/SP & $10 / 40 / 3$ & $5 / 20 / 4$ & \\
XELOX & 8 & 3 & \\
FM & 4 & 1 & \\
Unknown & 2 & 1 & \\
\hline
\end{tabular}

Group A, peritoneal recurrence with or without distant metastasis; group B, distant metastasis without peritoneal recurrence; $S D$ standard deviation

a Adjuvant chemotherapy regimen was not known because the patients had received it in another hospital

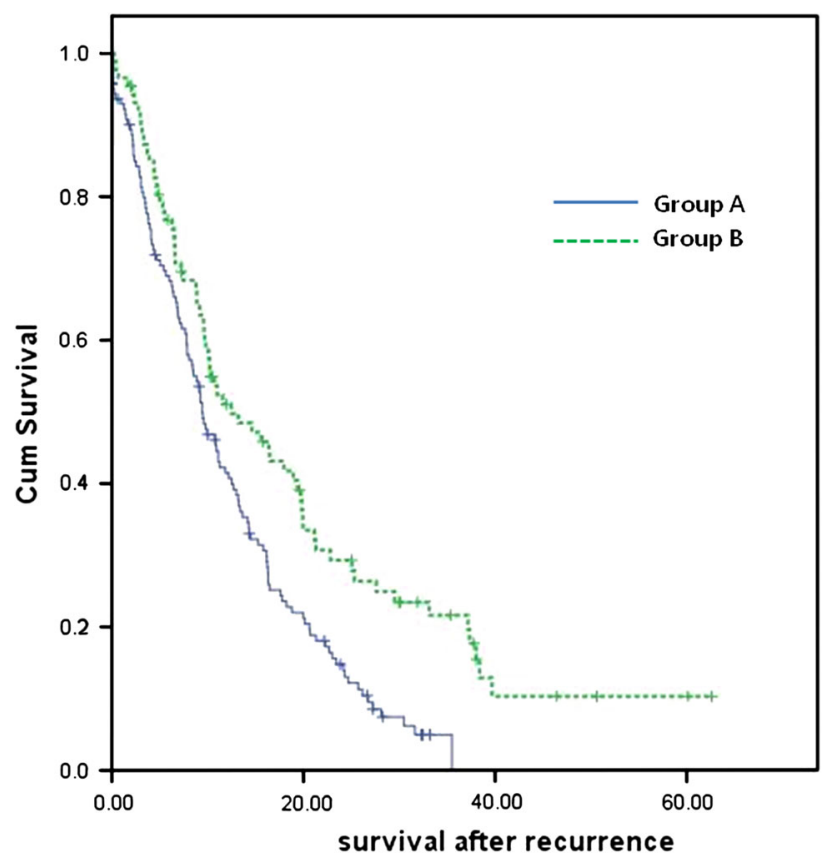

Fig. 2 Overall survival after recurrence according to the pattern of recurrence. Group A, patients who had peritoneal recurrence with or without distant metastasis; group B, patients who had distant metastasis without peritoneal recurrence. Cum cumulative

infiltrative type in Ming's classification, venous invasion, and tumor invasion depth $(\geq \mathrm{T} 3)$ were independent risk factors in the multivariate analysis (Table 3 ).

Derivation of the peritoneal recurrence risk index in patients who received adjuvant chemotherapy

This analysis was performed only in patients with history of adjuvant chemotherapy because that should be included in the protocol of prospective study. Two indexes were derived from the foregoing logistic regression analysis, which had evaluated risk factors for peritoneal recurrence. In the variable weight index, point values were assigned in proportion to the logistic regression model weight for each variable. In the equal weight model, 1 point was assigned to each variable except $\mathrm{T}$ stage ( 1 point for $\mathrm{T} 3$ and 2 points for T4 stage). ROC analysis showed no significant difference between the diagnostic performances of the models $(0.766 \pm 0.023$ vs. $0.760 \pm 0.024, p=0.380)$. Therefore, the peritoneal recurrence risk index was constructed with each risk factor assigned 1 point ( 2 points for T4 stage).

Rates of peritoneal recurrence with $0,1,2,3,4$ or 5 of points were $0 \%, 3.9 \%, 13.1 \%, 33.3 \%, 44.0 \%$, and $72.0 \%$, respectively, in patients who had received adjuvant chemotherapy. The cutoff point was 3.0 (sensitivity, $81.8 \%$; specificity, $61.1 \%$ ).

\section{Discussion}

Peritoneal carcinomatosis, once established, is associated with poor prognosis and a median survival of 1-6 months $[3,17,18]$. Our study also showed that the prognosis is poor with a median survival of 9.4 months after peritoneal recurrence, which was worse than that after distant metastasis without peritoneal recurrence (14.6 months). Therefore, prevention of peritoneal carcinomatosis is key to long-term survival. Adjuvant systemic chemotherapy has been recommended as the standard of care for resectable gastric cancer $[4,5]$; however, peritoneal recurrence is still the most common treatment failure after adjuvant systemic chemotherapy [4-6, 19]. In this study, peritoneal recurrence also occurred most frequently despite the fact that a number of patients with stages II and III (AJCC/ UICC 6th edition) received adjuvant systemic chemotherapy, except when the patients had poor general condition. Therefore, adjuvant IPC can be suggested as a method to reduce peritoneal recurrence. However, the role of adjuvant IPC in gastric cancer is still debated. We thus performed this study to determine the eligible patients for adjuvant IPC in prospective clinical study.

Several studies showed that IPC had a prophylactic benefit against peritoneal recurrence $[10,11,15,20]$. However, increased risk of postoperative complications was demonstrated by a meta-analysis [15]. Moreover, selected patients varied according to each study. These limitations make it difficult to apply IPC practically. This procedure should consequently only be considered for patients at high risk of peritoneal carcinomatosis. According to our results, Bormann type 4 gastric cancer, infiltrative type in Ming's classification, venous invasion, and tumor invasion depth $(\geq \mathrm{T} 3)$ were independent risk factors for peritoneal recurrence. Because each factor had a 
Table 2 Factors related to peritoneal recurrence in patients with advanced gastric cancer: univariate and multivariate analysis

\begin{tabular}{|c|c|c|c|c|c|c|c|}
\hline \multirow[t]{2}{*}{ Factors } & \multicolumn{4}{|c|}{ Univariate analysis } & \multicolumn{3}{|c|}{ Multivariate analysis } \\
\hline & $n$ & $\begin{array}{l}\text { Three-year } \\
\text { cumulative } \\
\text { incidence of } \\
\text { peritoneal } \\
\text { recurrence, \% }\end{array}$ & $\begin{array}{l}\text { Five-year } \\
\text { cumulative } \\
\text { incidence of } \\
\text { peritoneal } \\
\text { recurrence, \% }\end{array}$ & $p$ & Odds ratio & $95 \% \mathrm{CI}$ & $p$ \\
\hline Sex & & & & 0.251 & & & \\
\hline Male & 533 & 17.4 & 19.2 & & & & \\
\hline Female & 272 & 22.9 & 23.6 & & & & \\
\hline Age (years) & & & & 0.182 & & & \\
\hline$\leq 65$ & 502 & 20.5 & 22.6 & & & & \\
\hline$>65$ & 303 & 16.8 & 16.8 & & & & \\
\hline Bormann type & & & & $<0.001$ & & & \\
\hline $1-3$ & 711 & 15.0 & 16.2 & & 1.000 & & \\
\hline 4 & 84 & 52.6 & 56.7 & & 1.923 & $1.314-2.816$ & 0.001 \\
\hline Tumor size & & & & $<0.001$ & & & \\
\hline$\leq 5 \mathrm{~cm}$ & 381 & 10.3 & 10.3 & & 1.000 & & \\
\hline$>5 \mathrm{~cm}$ & 424 & 28.0 & 30.9 & & 1.136 & $0.743-1.736$ & 0.556 \\
\hline Histological grade & & & & $<0.001$ & & & \\
\hline Differentiated & 284 & 12.3 & 12.3 & & 1.000 & & \\
\hline Undifferentiated & 521 & 21.8 & 25.3 & & 1.460 & $0.511-4.172$ & 0.48 \\
\hline Lauren's classification & & & & $<0.001$ & & & \\
\hline Intestinal & 280 & 22.0 & 22 & & 1.000 & & \\
\hline Diffuse & 453 & 24.8 & 26.9 & & 0.801 & $0.273-2.353$ & 0.687 \\
\hline Mixed & 70 & 12.8 & 20.5 & & 0.667 & $0.224-1.991$ & 0.468 \\
\hline Ming's classification & & & & $<0.001$ & & & \\
\hline Expanding & 188 & 2.7 & 3.5 & & 1.000 & & \\
\hline Infiltrative & 617 & 24.4 & 26 & & 3.345 & $1.538-7.275$ & 0.002 \\
\hline Lymphatic invasion & & & & $<0.001$ & & & \\
\hline Negative & 227 & 9.9 & 11.9 & & 1.000 & & \\
\hline Positive & 578 & 23.2 & 24.4 & & 0.918 & $0.529-1.593$ & 0.76 \\
\hline Venous invasion & & & & $<0.001$ & & & \\
\hline Negative & 634 & 13.8 & 15 & & 1.000 & & \\
\hline Positive & 171 & 41.2 & 43.6 & & 1.618 & $1.414-2.295$ & 0.007 \\
\hline pT stage & & & & $<0.001$ & & & \\
\hline $\mathrm{T} 2$ & 206 & 1.5 & 1.5 & & 1.000 & & \\
\hline $\mathrm{T} 3$ & 308 & 13.0 & 13.4 & & 6.101 & $1.863-19.982$ & 0.003 \\
\hline $\mathrm{T} 4 \mathrm{a}$ & 256 & 39.0 & 43.7 & & 12.986 & $3.965-42.526$ & $<0.001$ \\
\hline $\mathrm{T} 4 \mathrm{~b}$ & 35 & 48.0 & 48.0 & & 12.447 & $3.406-45.488$ & $<0.001$ \\
\hline $\mathrm{pN}$ stage & & & & $<0.001$ & & & \\
\hline No & 210 & 5.3 & 7.4 & & 1.000 & & \\
\hline N1 & 136 & 11.5 & 11.5 & & 1.402 & $0.628-3.134$ & 0.41 \\
\hline $\mathrm{N} 2$ & 163 & 16.3 & 18.3 & & 1.634 & $0.768-3.476$ & 0.202 \\
\hline $\mathrm{N} 3$ & 296 & 36.1 & 37.4 & & 2.514 & $1.219-5.186$ & 0.013 \\
\hline Surgical approach & & & & 0.002 & & & \\
\hline Laparoscopy & 160 & & 88.5 & & 1.000 & & \\
\hline Open & 645 & & 77 & & 0.833 & $0.492-1.411$ & 0.497 \\
\hline Adjuvant chemotherapy & & & & $<0.001$ & & & \\
\hline No & 324 & 10.8 & 11.4 & & 1.000 & & \\
\hline Yes & 481 & 25.3 & 27.0 & & 1.053 & $0.699-1.587$ & 0.804 \\
\hline
\end{tabular}


Table 3 Factors related to peritoneal recurrence in patients who received adjuvant chemotherapy: univariate and multivariate analysis

\begin{tabular}{|c|c|c|c|c|c|c|c|}
\hline \multirow[t]{2}{*}{ Factors } & \multicolumn{4}{|c|}{ Univariate analysis } & \multicolumn{3}{|c|}{ Multivariate analysis } \\
\hline & $n$ & $\begin{array}{l}\text { Three-year } \\
\text { cumulative } \\
\text { incidence of } \\
\text { peritoneal } \\
\text { recurrence, \% }\end{array}$ & $\begin{array}{l}\text { Five-year } \\
\text { cumulative } \\
\text { incidence of } \\
\text { peritoneal } \\
\text { recurrence, \% }\end{array}$ & $p$ & Odds ratio & $95 \% \mathrm{CI}$ & $p$ \\
\hline Sex & & & & 0.203 & & & \\
\hline Male & 315 & 22.6 & 24.6 & & & & \\
\hline Female & 166 & 30.4 & 31.6 & & & & \\
\hline Age (years) & & & & 0.255 & & & \\
\hline$\leq 65$ & 347 & 26.7 & 28.9 & & & & \\
\hline$>65$ & 134 & 21.2 & 21.2 & & & & \\
\hline Bormann type & & & & $<0.001$ & & & \\
\hline $1-3$ & 412 & 20.7 & 21.8 & & 1.000 & & \\
\hline 4 & 69 & 54.1 & 59.8 & & 1.851 & $1.197-2.863$ & 0.006 \\
\hline Tumor size & & & & $<0.001$ & & & \\
\hline$\leq 5 \mathrm{~cm}$ & 197 & 16.2 & 16.2 & & 1.000 & & \\
\hline$>5 \mathrm{~cm}$ & 284 & 32.3 & 35.5 & & 1.117 & $0.702-1.778$ & 0.639 \\
\hline Histological grade & & & & $<0.001$ & & & \\
\hline Differentiated & 146 & 18 & 18 & & 1.000 & & \\
\hline Undifferentiated & 334 & 28.7 & 31.1 & & 1.226 & $0.390-3.852$ & 0.728 \\
\hline Lauren's classification & & & & 0.004 & & & \\
\hline Intestinal & 143 & 17.6 & 17.6 & & 1.000 & & \\
\hline Diffuse & 299 & 31 & 33.1 & & 0.831 & $0.256-2.702$ & 0.759 \\
\hline Mixed & 38 & 10.9 & 16.9 & & 0.558 & $0.158-1.968$ & 0.364 \\
\hline Ming's classification & & & & $<0.001$ & & & \\
\hline Expanding & 80 & 5.3 & 5.3 & & 1.000 & & \\
\hline Infiltrative & 401 & 29.2 & 31.2 & & 3.185 & $1.275-7.961$ & 0.013 \\
\hline Lymphatic invasion & & & & 0.446 & & & \\
\hline Negative & 74 & 19.4 & 25.4 & & & & \\
\hline Positive & 407 & 26.6 & 27.3 & & & & \\
\hline Venous invasion & & & & $<0.001$ & & & \\
\hline Negative & 357 & 17.9 & 20.1 & & 1.000 & & \\
\hline Positive & 124 & 47.9 & 47.9 & & 1.737 & $1.148-2.629$ & 0.009 \\
\hline pT stage & & & & $<0.001$ & & & \\
\hline $\mathrm{T} 2$ & 78 & 2.6 & 2.6 & & 1.000 & & \\
\hline $\mathrm{T} 3$ & 176 & 16.2 & 17 & & 5.091 & $1.201-21.585$ & 0.027 \\
\hline $\mathrm{T} 4 \mathrm{a}$ & 200 & 41 & 44.8 & & 10.092 & $2.385-42.700$ & 0.002 \\
\hline $\mathrm{T} 4 \mathrm{~b}$ & 27 & 43.9 & 44 & & 8.297 & $1.743-39.494$ & 0.008 \\
\hline pN stage & & & & $<0.001$ & & & \\
\hline No & 29 & 17.2 & 31.7 & & 1.000 & & \\
\hline N1 & 91 & 11.3 & 11.3 & & 0.767 & $0.278-2.117$ & 0.608 \\
\hline $\mathrm{N} 2$ & 117 & 16.4 & 17.8 & & 0.933 & $0.360-2.416$ & 0.886 \\
\hline N3 & 244 & 37 & 37.7 & & 1.649 & $0.682-3.987$ & 0.266 \\
\hline Surgical approach & & & & 0.038 & & & \\
\hline Laparoscopy & 85 & 18 & 18 & & 1.000 & & \\
\hline Open & 396 & 27 & 29 & & 1.393 & $0.770-2.519$ & 0.273 \\
\hline
\end{tabular}


different impact on peritoneal recurrence, the peritoneal recurrence risk index was constructed. Although a variable weight index can most accurately predict peritoneal recurrence, the equal weight model was comparable to that and appeared simple for patient selection in future clinical trials. Our data showed that patients with at least 3 points in the index had an increased risk for peritoneal recurrence with $81.8 \%$ sensitivity and $61.1 \%$ specificity. Therefore, adjuvant IPC should be considered in those patients in a future study.

Yoo et al. [3] reported that younger age, infiltrative or diffuse type, undifferentiated tumor, and total gastrectomy including serosal invasion and lymph node metastasis were independent risk factors related to peritoneal recurrence. Bando et al. [21] reported that depth of invasion (serosal involvement), tumor size, infiltrative growth pattern, and positive cytological examination were significantly and independently related to peritoneal recurrence; however, these studies analyzed patients who underwent curative resection only, without consideration for adjuvant chemotherapy. Because nowadays adjuvant systemic chemotherapy is generally accepted in treatment of advanced gastric cancer, the analysis of risk factors related to peritoneal recurrence in patients receiving adjuvant chemotherapy is mandatory to select patients eligible for IPC in a future study. A recently published study showed that tumor diameter $(>7 \mathrm{~cm})$ and lymph node metastasis (N3) were significant independent risk factors for peritoneal recurrence after adjuvant S-1 chemotherapy [6]. By contrast, in our study, tumor depth ( $\geq \mathrm{T} 3$ ), diffuse growth pattern (Bormann type 4), infiltrative type in Ming's classification, and venous invasion were independent risk factors. Tumor size was not an independent risk factor in any size criteria $(5 \mathrm{~cm}$ or $7 \mathrm{~cm}$; data for tumor size criterion of $7 \mathrm{~cm}$ not shown), and lymph node metastasis lost statistical significance in this subgroup analysis. These inconsistent results may be because the adjuvant chemotherapy regimen used in our study has changed over time according to reported evidence. In Korea, nowadays the XELOX regimen (capecitabine plus cisplatin) is a popular method for adjuvant chemotherapy. Therefore, whether IPC with adjuvant XELOX therapy will be effective to prevent peritoneal recurrence should be addressed in a future study.

Serosal invasion was consistently reported as a significant risk factor for peritoneal recurrence [3, 21, 22], and some authors have reported that gastric cancer patients with serosal invasion have shown significant improvement in survival when treated with IPC in randomized controlled studies [10, 23]. Similar to previous studies, the present study showed that depth of tumor invasion was the most important risk factor regardless of adjuvant chemotherapy administration. In contrast to previous studies, subserosa (pT3) as well as serosa invasion stage was also a significant risk factor for peritoneal recurrence, with a 5-year cumulative incidence of $13.4 \%$. Another retrospective study had reported that pT3 as well as pT4a benefited from adjuvant IPC [20]. The potential benefit of adjuvant IPC in patients with pT3 stage should be proven again in prospective studies.

Intraperitoneal free cancer cells are another important risk factor for peritoneal recurrence [21, 24]. One of the limitations of the present study is that the peritoneal cytology result was not included in the analysis of risk factors for peritoneal recurrence because peritoneal washing cytology was not routine procedure in Korea. Evidence is sufficient to include patients with intraperitoneal free cancer cells as indication for adjuvant IPC [21, 24, 25]; however, a positive cytology result $(\mathrm{CY}+)$ cannot be the only indication for adjuvant IPC because conventional cytology examination lacks sensitivity $[21,26]$. Several studies were conducted to improve sensitivity using immunological methods with selected monoclonal antibodies or real-time polymerase chain reaction for detection of free cancer cells in the peritoneal washes [26-28], but these means are not generally available during the operation. From these aspects, prediction of peritoneal recurrence according to clinicopathological factors should be considered simultaneously to determine the indication of adjuvant IPC.

A small number of investigators reported that laparoscopic gastrectomy was oncologically a safe procedure for AGC with long-term outcomes similar to those for open surgery [29, 30]. This study also showed that the laparoscopic procedure did not increase peritoneal recurrence. In our center, laparoscopic gastrectomy was performed in patients diagnosed with cT1N0M0 to cT2N0M0 gastric cancer before October 2008 and the indication for laparoscopic gastrectomy was then extended to all resectable gastric cancers. Therefore, as with previous studies, our result is not conclusive because of a selection bias resulting from different indications for open and laparoscopic gastrectomy. However, we can suggest that laparoscopic gastrectomy with adjuvant IPC can be applied. The safety and feasibility of laparoscopic gastrectomy with adjuvant IPC for selective AGC should be assessed in a future study.

In conclusion, peritoneal recurrence is a dismal condition that requires aggressive treatment to prevent. Greater than T3 tumor invasion, extensive lymph node metastasis (N3), Bormann type 4 gastric cancer, infiltrative type according to Ming's classification, and presence of venous invasion were independent risk factors for peritoneal recurrence, and N3 stage lost significance in the presence of adjuvant chemotherapy history. Among patients who had received adjuvant chemotherapy, those with at least 3 points in the index developed by our study had an increased risk for peritoneal recurrence. Future clinical studies on IPC should target the patients that meet this criterion as 
these subgroups are most likely to have peritoneal recurrence, according to our study.

Acknowledgments This study was supported by Seoul National University Bundang Hospital (project no. 03-2010-019).

\section{References}

1. Ferlay J, Shin HR, Bray F, Forman D, Mathers C, Parkin DM. Estimates of worldwide burden of cancer in 2008: GLOBOCAN 2008. Int J Cancer. 2010;127:2893-917.

2. Parkin DM, Bray F, Ferlay J, Pisani P. Global cancer statistics, 2002. CA Cancer J Clin. 2005;55:74-108.

3. Yoo CH, Noh SH, Shin DW, Choi SH, Min JS. Recurrence following curative resection for gastric carcinoma. $\mathrm{Br} \mathrm{J}$ Surg. 2000;87:236-42.

4. Sakuramoto S, Sasako M, Yamaguchi T, Kinoshita T, Fujii M, Nashimoto A, et al. Adjuvant chemotherapy for gastric cancer with S-1, an oral fluoro pyrimidine. N Engl J Med. 2007;357(18): 1810-20 (Erratum in: N Engl J Med 2008;358(18):1977).

5. Macdonald JS, Smalley SR, Benedetti J, Hundahl SA, Estes NC, Stemmermann GN, et al. Chemoradiotherapy after surgery compared with surgery alone for adenocarcinoma of the stomach or gastroesophageal junction. N Engl J Med. 2001;345(10): 725-30.

6. Aoyama T, Yoshikawa T, Hayashi T, Kuwabara H, Mikayama Y, Ogata T, et al. Risk factors for peritoneal recurrence in stage II/III gastric cancer patients who received S-1 adjuvant chemotherapy after D2 gastrectomy. Ann Surg Oncol. 2012;19(5):1568-74.

7. Sakamoto J, Matsui T, Kodera Y. Paclitaxel chemotherapy for the treatment of gastric cancer. Gastric Cancer. 2009;12(2):69-78.

8. Yonemura Y, Ninomiya I, Kaji M, Sugiyama K, Fujimura T, Sawa T, et al. Prophylaxis with intraoperative chemo hyperthermia against peritoneal recurrence of serosal invasion-positive gastric cancer. World J Surg. 1995;19:450-5.

9. Dedrick R. Theoretical and experimental bases of intraperitoneal chemotherapy. Semin Oncol. 1985;12:1-6.

10. Yonemura Y, de Aretxabala X, Fujimura T, Fushida S, Katayama K, Bandou E, et al. Intraoperative chemohyperthermic peritoneal perfusion as an adjuvant to gastric cancer: final results of a randomized controlled study. Hepatogastroenterology. 2001;48(42):1776-82.

11. Yu W, Whang I, Suh I, Averbach A, Chang D, Sugarbaker PH. Prospective randomized trial of early postoperative intraperitoneal chemotherapy as an adjuvant to resectable gastric cancer. Ann Surg. 1998;228(3):347-54.

12. Yonemura Y, Kawamura T, Bandou E, Takahashi S, Sawa T, Matsuki N. Treatment of peritoneal dissemination from gastric cancer by peritonectomy and chemohyperthermic peritoneal perfusion. Br J Surg. 2005;92(3):370-5.

13. Yang XJ, Huang CQ, Suo T, Mei LJ, Yang GL, Cheng FL, et al. Cytoreductive surgery and hyperthermic intraperitoneal chemotherapy improves survival of patients with peritoneal carcinomatosis from gastric cancer: final results of a phase III randomized clinical trial. Ann Surg Oncol. 2011;18(6):1575-81.

14. Glehen O, Gilly FN, Arvieux C, Cotte E, Boutitie F, Mansvelt B, et al. Association Française de Chirurgie. Peritoneal carcinomatosis from gastric cancer: a multi-institutional study of 159 patients treated by cytoreductive surgery combined with perioperative intraperitoneal chemotherapy. Ann Surg Oncol. 2010;17(9):2370-7.

15. Yan TD, Black D, Sugarbaker PH, Zhu J, Yonemura Y, Petrou G, et al. A systematic review and meta-analysis of the randomized controlled trials on adjuvant intraperitoneal chemotherapy for resectable gastric cancer. Ann Surg Oncol. 2007;14(10):2702-13.

16. Japanese Gastric Cancer Association. Japanese classification of gastric carcinoma, 2nd English edition. Gastric Cancer. 1998;1:10-24.

17. Chu DZ, Lang NP, Thompson C, Osteen PK, Westbrook KC. Peritoneal carcinomatosis in nongynecologic malignancy. A prospective study of prognostic factors. Cancer (Phila). 1989;63(2):364-7.

18. Sadeghi B, Arvieux C, Glehen O, Beaujard AC, Rivoire M, Baulieux J, et al. Peritoneal carcinomatosis from non-gynecologic malignancies: results of the EVOCAPE 1 multicentric prospective study. Cancer (Phila). 2000;88(2):358-63.

19. Ajani JA, Ota DM, Jessup JM, Ames FC, McBride C, Boddie A, et al. Resectable gastric carcinoma. An evaluation of preoperative and postoperative chemotherapy. Cancer (Phila). 1991;68(7):1501-6.

20. Shi C, Yang B, Chen Q, Yang J, Fan N. Retrospective analysis of adjuvant intraperitoneal chemotherapy effect prognosis of resectable gastric cancer. Oncology. 2011;80(5-6):289-95.

21. Bando E, Yonemura Y, Takeshita Y, Taniguchi K, Yasui T, Yoshimitsu Y, et al. Intraoperative lavage for cytological examination in 1,297 patients with gastric carcinoma. Am J Surg. 1999; 178(3):256-62.

22. Sun Z, Xu YY, Wang ZN, Zhu Z, Zhang H, Huang BJ, et al. Macroscopic serosal classification predicts peritoneal recurrence for patients with gastric cancer underwent potentially curative surgery. Ann Surg Oncol. 2011;18(4):1068-80.

23. Yu W, Whang I, Chung HY, Averbach A, Sugarbaker PH. Indications for early postoperative intraperitoneal chemotherapy of advanced gastric cancer: results of a prospective randomized trial. World J Surg. 2001;25(8):985-90.

24. Kodera Y, Yamamura Y, Shimizu Y, Torii A, Hirai T, Yasui K, et al. Peritoneal washing cytology: prognostic value of positive findings in patients with gastric carcinoma undergoing a potentially curative resection. J Surg Oncol. 1999;72(2):60-4 (discussion 64-65).

25. Kuramoto M, Shimada S, Ikeshima S, Matsuo A, Yagi Y, Matsuda $\mathrm{M}$, et al. Extensive intraoperative peritoneal lavage as a standard prophylactic strategy for peritoneal recurrence in patients with gastric carcinoma. Ann Surg. 2009;250(2):242-6.

26. Benevolo M, Mottolese M, Cosimelli M, Tedesco M, Giannarelli D, Vasselli S, et al. Diagnostic and prognostic value of peritoneal immunocytology in gastric cancer. J Clin Oncol. 1998;16:3406-11.

27. Tamura N, Iinuma $H$, Takada $T$. Prospective study of the quantitative carcinoembryonic antigen and cytokeratin 20 mRNA detection in peritoneal washes to predict peritoneal recurrence in gastric carcinoma patients. Oncol Rep. 2007;17:667-72.

28. Kodera Y, Nakanishi H, Ito S, Yamamura Y, Kanemitsu Y, Shimizu Y, et al. Quantitative detection of disseminated free cancer cells in peritoneal washes with real-time reverse transcriptasepolymerase chain reaction. Ann Surg. 2002;235:499-506.

29. Hamabe A, Omori T, Tanaka K, Nishida T. Comparison of longterm results between laparoscopy-assisted gastrectomy and open gastrectomy with D2 lymph node dissection for advanced gastric cancer. Surg Endosc. 2012;26(6):1702-9.

30. Park DJ, Han SU, Hyung WJ, Kim MC, Kim W, Ryu SY, Korean Laparoscopic Gastrointestinal Surgery Study (KLASS) group, et al. Long-term outcomes after laparoscopy-assisted gastrectomy for advanced gastric cancer: a large-scale multicenter retrospective study. Surg Endosc. 2012;26(6):1548-53. 